\title{
Influência de tempo e da temperatura de armazenamento de sangue de equino submetido a análises bioquímicas
}

Matheus Morillo Bär", Felipe Eduardo Dal Mas, Luana Gomes Fernandes, Maria Vitória Ferreira Barreiros, Lindomar Fernandes Pessoa, Marla Schneider, Leiluana Camila Rettig, Pedro Argel Zadinelo Morreira, Marilene Machado Silva, Erica Cristina Bueno do Prado Guirro

Universidade Federal do Paraná (UFPR), Palotina, PR, Brasil

*Autor correspondente

e-mail: barmatheus2103@gmail.com

\section{Resumo}

O uso de exames laboratoriais é prática cada vez mais frequente na medicina veterinária, uma vez que seus resultados são de grande valor diagnóstico. No entanto, a campo, o uso desta alternativa por médicos veterinários autônomos é restrito, uma vez que é necessário o encaminhamento das amostras a um laboratório de análises clínicas, o qual nem sempre está próximo ao local do atendimento. Hoje, considerase que a amostra permanece viável para a análise se esta for acondicionada entre 2 e $8{ }^{\circ} \mathrm{C}$ por até 24 horas. Assim, determinar o tempo e a temperatura ideal de armazenamento para mater a viabilidade da amostra é de suma importância, oferecendo segurança na interpretação dos resultados, o qual é o objetivo de estudo do presente trabalho. Para realização deste experimento foi coletado sangue venoso de oito equinos hígidos, $112 \mathrm{ml}$ de cada animal, distribuídos em 14 tubos com fluoreto de sódio + EDTA K3, utilizados para a determinação da concentração de glicose e lactato plasmática, e 14 tubos secos, utilizados para a determinação dos demais marcadores, sendo sete de cada um desses tubos mantidos sob refrigeração $\left(4^{\circ} \mathrm{C}\right)$ ou em temperatura ambiente $\left(22^{\circ} \mathrm{C}\right)$. Com estas amostras foram realizados exames bioquímicos utilizando kits comerciais LabTest ${ }^{\circledR}$ para determinação de atividade enzimática de aspartato aminotransferase (AST), creatinina quinase (CK), gama-glutamil transferase (GGT), concentrações de glicose (GLI), lactato (LACT), ureia, creatinina (CREAT), proteínas séricas totais (PTN) e albumina (ALB) em T0 (imediatamente após a coleta) e após duas (T2), quatro (T4), oito (T8), 12 (T12), 24 (T24) e 48 horas (T48). A análise dos dados foi baseada nas médias obtidas em cada tempo, sendo que estas poderiam ter seu processamento interrompido caso os valores da alíquota diferissem mais que 6\%, acima ou abaixo, dos valores obtidos em T0. 0 tempo máximo de cada variável em temperatura ambiente e sob refrigeração foi respectivamente: AST T2 (135,1 $\pm 55,3)$ e T0 (157,0 \pm 61,1); CK T0 (207,5 \pm 41,5) e T24 (187,5 $\pm 34,2)$; GGT T4 (20,3 $\pm 2,7 ;)$ e T24 (18,8 \pm 2,5;); GLI T24 (86,6 $\pm 5,3 ;)$ е T24 (89,5 $\pm 5,6)$; LACT T2 $(6,2 \pm 1,5)$ e T4 $(5,7 \pm 1,2) ;$ ureia T48 $(39,9 \pm 2,9)$ e 
T8 (39,8 \pm 7,2); CREAT T24 (1,5 \pm 0,1) e T12 (1,6 \pm 0,2); PTN T24 (7,3 \pm 0,5) e T24 (7,2 \pm 0,5); ALB T24 (2,7 $\pm 0,1)$ e T48 $(2,8 \pm 0,2)$. Assim, pode-se concluir que em temperatura ambiente de $22^{\circ} \mathrm{C}$ marcadores como glicose, proteínas séricas totais, albumina e creatinina permanecem viáveis por até 24 horas após a coleta, ao passo que enzimas como a AST e GGT se alteram poucas horas após a coleta. No caso destas amostras permanecerem em refrigeração de $4{ }^{\circ} \mathrm{C}$, notou-se que enzimas como GGT e CK permaneceram estáveis por até 24 horas após a coleta.

Palavras-chave: Cavalo. Estocagem. Patologia clínica. 